Bar-Kochva, Irit; Hasselhorn, Marcus

\title{
In search of methods enhancing fluency in reading. An examination of the relations between time constraints and processes of reading in readers of
}

\section{German}

formal und inhaltlich überarbeitete Version der Originalveröffentlichung in:

formally and content revised edition of the original source in:

Journal of experimental child psychology 140 (2015), S. 140-157

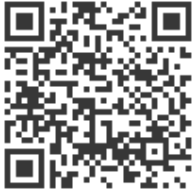

Bitte verwenden Sie in der Quellenangabe folgende URN oder DOI /

Please use the following URN or DOI for reference:

urn:nbn:de:0111-pedocs-178751

$10.25656 / 01: 17875$

https://nbn-resolving.org/urn:nbn:de:0111-pedocs-178751

https://doi.org/10.25656/01:17875

\section{Nutzungsbedingungen}

Dieses Dokument steht unter folgender Creative Commons-Lizenz: http://creativecommons.org/licenses/by-nc-nd/4.0/deed.de - Sie dürfen das Werk bzw. den Inhalt unter folgenden Bedingungen vervielfältigen, verbreiten und öffentlich zugänglich machen: Sie müssen den Namen des Autors/Rechteinhabers in der von ihm festgelegten Weise nennen. Dieses Werk bzw. dieser Inhalt darf nicht für kommerzielle Zwecke verwendet werden und es darf nicht bearbeitet, abgewandelt oder in anderer Weise verändert werden.

Mit der Verwendung dieses Dokuments erkennen Sie die Nutzungsbedingungen an.

\section{Terms of use}

This document is published under following Creative Commons-License: http://creativecommons.org/licenses/by-nc-nd/4.0/deed.en - You may copy, distribute and transmit, adapt or exhibit the work in the public as long as you attribute the work in the manner specified by the author or licensor. You are not allowed to make commercial use of the work or its contents. You are not allowed to alter, transform, or change this work in any other way.

By using this particular document, you accept the above-stated conditions of use.

\section{Kontakt / Contact:}

peDOCS

DIPF | Leibniz-Institut für Bildungsforschung und Bildungsinformation Informationszentrum (IZ) Bildung

E-Mail:pedocs@dipf.de

Internet: www.pedocs.de

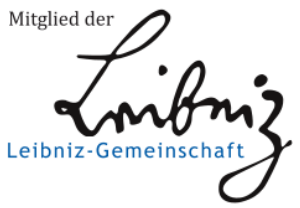




\section{In search of methods enhancing fluency in reading: An examination of the relations between time constraints and processes of reading in readers of German}

Irit Bar-Kochvaa,b,c,d, Marcus Hasselhorn ${ }^{a, b, c}$

${ }^{a}$ Department of Psychology, Goethe University, 60054 Frankfurt am Main, Germany

${ }^{b}$ German Institute for International Educational Research (DIPF), 60486 Frankfurt am Main, Germany

${ }^{\mathrm{c}}$ Center for Individual Development and Adaptive Education of Children at Risk (IDeA), 60486 Frankfurt am Main, Germany

${ }^{d}$ Edmond J. Safra Brain Research Center for the Study of Learning Disabilities, University of Haifa, Haifa, Israel

\section{Abstract}

The attainment of fluency in reading is a major difficulty for reading-disabled people. Manipulations applied on the presentation of texts, leading to "on-line" effects on reading (i.e., while texts are manipulated), are one direction of examinations in search of methods affecting reading. The imposing of time constraints, by deleting one letter after the other from texts presented on a computer screen, has been established as such a method. In an attempt to further understand its nature, we tested the relations between time constraints and processes of reading: phonological decoding of small orthographic units and the addressing of orthographic representations from the mental lexicon. We also examined whether the type of orthographic unit deleted (lexical, sublexical, or nonlexical unit) has any additional effect. Participants were German fifth graders with $(n=29)$ or without $(n=34)$ reading disability. Time constraints enhanced fluency in reading in both groups, and to a similar extent, across conditions. Comprehension was unimpaired. These results place the very principle of time constraints, regardless of the orthographic unit manipulated, as a critical factor affecting fluency in reading. However, phonological decoding explained a significant amount of variance in fluency in reading across all conditions in reading-disabled children, whereas the addressing of orthographic representations was the consistent predictor of fluency in reading in regular readers. These results indicate a qualitative difference in the processes explaining the variance in fluency in reading in regular and reading-disabled readers and suggest that time constraints might not have an effect on the relations between these processes and reading performance.

Keywords: reading, dyslexia, reading acceleration, lexicon, morphology, fluency

\section{Introduction}

The development of methods that have an effect on reading performance is highly challenging. To date, the most extensively studied methods are the training of phonological and orthographic skills. Phonological training has shown positive effects on decoding but limited effects on fluency in reading (for a review, see Meyer \& Felton, 1999), which is a central skill of reading proficiency (Breznitz, 2006, 2008; Fletcher, 2009; Lyon, Shaywitz, \& Shaywitz, 2003). The central assumption guiding the vast majority of studies focusing on improving fluency in reading is that it depends on the scope and quality of stored orthographic representations. Consequently, training consists mainly of repeated exposures to the same orthographic items (e.g., Kuhn \& Stahl, 2003; Meyer \& Felton, 1999; Roberts, 
Torgesen, Boardman, \& Scammacca, 2008; Wolf \& Katzir-Cohen, 2001). Positive effects were, however, found primarily on trained items (Roberts et al., 2008; Thaler, Ebner, Wimmer, \& Landerl, 2004). Despite the important role of these types of training in advancing children with reading disability, they often require numerous sessions until progress is evident, as well as the mediation of a tutor, with its inevitable financial and logistic complications.

Different manipulations carried out on the presentation of texts, which lead to "on-line" effects on reading (i.e., while texts are manipulated), are another direction of examinations in search of methods affecting reading. Unless administered in the framework of a training program, such manipulations might not be expected to lead to long-term effects on reading or to effects of transfer to untrained material; nevertheless, they can be easily implemented using current technological devices, thereby having the potential of facilitating reading in everyday life settings. In addition, these methods do not require the mediation of a tutor and, therefore, are accessible for various populations. In such a recently examined manipulation, the mere increase of space between letters led to improved accuracy and fluency in reading in Italian and French reading-disabled children (8-14 years of age). The researchers suggested that the manipulation reduced negative effects on reading resulting from a difficulty of people with reading disability to process crowded visual information (Zorzi et al., 2012).

The current study focused on another example of this kind of manipulation, termed "reading acceleration" (Breznitz, 2006). This manipulation consists of time constraints imposed on reading by erasing texts presented on a computer screen one letter after the other. The pace at which the letters are deleted is based on the maximal (or mean; see Horowitz-Kraus, Cicchino, Amiel, Holland, \& Breznitz, 2014) individual per-letter reading rate measured in a self-paced reading condition preceding the fast-paced condition. This manipulation was found to have positive on-line effects on fluency in reading while comprehension stays the same, and in some studies it was even found to improve compared with a self-paced reading condition and, therefore, was termed the "acceleration phenomenon" (Breznitz, 1987a, 1987b, 1988, 1997a, 1997b; Breznitz, DeMarco, \& Hakerem, 1993; Breznitz, DeMarco, Shammi, \& Hakerem, 1994). The time constraints were suggested to encourage fast processing, reduce distractibility, increase attention capacity, and increase the units available in short-term memory before they decay (Breznitz, 1988, 1997a, 2008; Breznitz \& Leiken, 2000; Breznitz \& Share, 1992; Leiken \& Breznitz, 2001). Several other explanations were proposed relating the acceleration phenomenon to the processes underlying reading: phonological decoding and lexical access. The time constraints were suggested to enhance word retrieval from the mental lexicon and to shift the emphasis away from the impaired phonological route of reading-disabled children (Breznitz, 1987a, 1997b, 2002; Karni et al., 2005). However, whether the imposing of time constraints actually changes the relations of reading with these underlying processes is yet unclear. With the goal of deepening the understanding of the effects of time constraints on reading, the examination of these relations was the focus of this study.

\section{Processes underlying reading}

Two main processes underlying word recognition were suggested and may coarsely be described as a process of grapheme-phoneme conversion and a process in which orthography is mapped onto meaning through direct addressing of stored lexical representations. Neuroimaging data have accumulated to suggest that these are associated with left hemisphere systems; the first is related to a dorsal system, and the second is related to a more ventral system (Shaywitz \& Shaywitz, 2008). 
Much has been debated between the dual-route and parallel distributed processing (PDP) approaches and their developments and versions (e.g., Coltheart, 2005; Harm \& Seidenberg, 2004; Plaut, 2005) on whether and how these processes interact, how orthography is represented in the mental lexicon, and whether prelexical phonology is mandatory in word reading (Coltheart, 1978, 2005; Frost, 1998). Nevertheless, there appears to be a consensus in the developmental literature on reading acquisition (Ehri, 2005; Frith, 1985; Share, 1995), according to which reading progresses from phonological decoding of each grapheme into its corresponding phoneme to a more efficient process of reading involving the addressing of stored lexical representations (i.e., from the dorsal system to the ventral system). The latter was suggested to shorten word recognition time (Ehri, 2005; Harm \& Seidenberg, 2004), allowing cognitive resources to be directed to comprehension. It should be noted, however, that this does not mean that phonological decoding of sublexical orthographic units is not involved in skilled reading (Katz \& Frost, 1992); instead, it is suggested that the involvement of familiar orthographic units represented in the mental lexicon takes an increasing role with development (Ehri, 2005; Frith, 1985).

Studies indicate that phonological deficits continue to characterize struggling readers even during adulthood (Bruck, 1990, 1992). Deficient phonological decoding was suggested to hamper the acquisition of orthographic representations (Share, 1995). If orthographic representations are lacking, the direct addressing of the lexicon in search of orthographic representations would be inefficient. Indeed, people with reading disability were found to involve phonological processing in reading more than their peers despite a considerable number of years of reading experience (Bruck, 1990). At the same time, this appears not to be an "all-or-none" situation; children with reading disability in the fourth to sixth grades were found to be able to acquire orthographic representations following just a few exposures to unfamiliar words (Share \& Shalev, 2004). In addition, representations of morphemes (the smallest linguistic units to convey meanings) were found to be available in reading to children and adults with or without reading disability (Burani, Marcolini, De Luca, \& Zoccolotti, 2008; Leiken \& Even Zur, 2006; Traficante, Marcolini, Luci, Zoccolotti, \& Burani, 2011; Verhoeven \& Schreuder, 2011; but see Deacon, Parrila, \& Kirby, 2006; Raveh \& Schiff, 2008; Schiff \& Raveh, 2007).

Taking into account that people with reading disability establish an orthographic lexicon to some extent, one way in which time constraints could have an effect on fluency in reading is by encouraging an increase in the weight of the addressed process in reading at the expense of the slower (and often inefficient; Bruck, 1990) phonological one. It should also be mentioned that slow processing of the print, often characterizing people with reading disability (Breznitz, 2006), was suggested to hamper the acquisition of orthographic representations by interrupting the integration of single letters into recurring orthographic chunks because the duration for which each of the letters can be held in working memory is limited (Bowers \& Wolf, 1993; Breznitz, 2006, 2008; Farmer \& Klein, 1995; Kail \& Hall, 1994). Based on the same rationale, even if a word's orthographic representation is available in the mental lexicon, slow processing of the print in reading may interrupt the perception of the letters composing the same word as a familiar orthographic chunk. As a result, there will be no automatic match between the orthographic units perceived in reading and the representations in the mental lexicon. The imposing of time constraints may encourage the processing of orthographic units more efficiently in the working memory, as suggested previously (Breznitz \& Share, 1992), and may consequently lead to their processing as familiar and integrated units. 


\section{The current study}

In an attempt to shed light on the possible effects of time constraints on the processes involved in reading, the relations between reading with and without time constraints and tasks involving phonological decoding (reading of pseudowords) and the addressing of orthographic representations (spelling of real words) were examined. Participants were fifth graders from Germany, both regular readers and reading-disabled children. The reviewed literature suggests that under regular reading conditions (without time constraints), phonological decoding would be more related to fluency in reading in reading-disabled children than in regular readers, whereas the addressing of orthographic representations would be more related to fluency in reading in regular readers. A change in these relations when time constraints are imposed would suggest that this manipulation has an effect on the processes explaining the variance in reading.

It was also considered that limiting the duration of presentation of texts by deleting one letter after the other (as studied so far) may be suboptimal because it is possible that it directs the readers into serial processing of single letters. However, imposing time constraints on the presentation of a lexical unit (i.e., all letters of a lexical unit are deleted at the same time) may further encourage the addressing of orthographic lexical representations in reading. The mental lexicon was suggested to consist of representations of morphemes and of whole words (Clahsen, 1999; Deutsch, Frost, \& Forster, 1998). Therefore, two lexical conditions were tested in addition to the deletion of single letters. In one condition whole words were deleted, and in the other condition the words were morphologically parsed by deleting prefixes, word stems, and suffixes as separate units. It was also considered that the deletion of texts in the letter-by-letter condition progresses in a constant unit of one letter per deleted item. In the two lexical conditions, however, the size of the units deleted varies in accordance with the length of the morpheme, prefix, suffix, or word deleted. This raises the concern that consistency in the size of the unit deleted would be an intervening factor. To disentangle this variable from the variable of lexicality, a fourth condition was introduced in which units of letters of random sizes, which did not carry a lexical meaning, were deleted (all letters of such a unit were deleted at the same time).

It should be stressed that here we examined the possible effects of time constraints on reading while they were imposed. Long-term effects on reading or effects of transfer to reading without time constraints may be expected only after a considerable period of training (e.g., Breznitz et al., 2013; Snellings, van der Leij, de Jong, \& Blok, 2009), particularly in children with reading experience of several years who have already established inefficient processes of reading. Nevertheless, the examination of different manipulations, which may facilitate reading on-line, is scarce. In view of the practical advantages that such manipulations may offer, it is important to acquire better understanding of their nature, potential, and limitations.

\section{Method}

\section{Participants}

A total of 161 fifth graders, learning in the regular educational system in Germany, were recruited. The rationale for the examination of this age group was that German readers were expected to have established orthographic representations by this grade, at least of age-appropriate words, because German readers reach accuracy in reading very quickly, similarly to readers of other orthographies 
with transparent grapheme-phoneme relations (Aro \& Wimmer, 2003; Mann \& Wimmer, 2002; Seymour, Aro, \& Erskine, 2003).

The children were recruited from two schools in the urban area of Frankfurt am Main. In this area, there are many families with migration backgrounds. Children were included in analyses only if they were born in Germany, attended the German-speaking educational system since early childhood, and reached a vocabulary score that was at least in the average range. A total of 146 children attained these criteria; however, 4 participants needed to be excluded due to a coding error. This left 142 children in the total sample (71 boys, mean age $=11.49$ years, $S D=0.51)$. Two groups were then extracted out of this sample: children with reading disability and regular readers. A reading score at the 25th percentile or less on a normed German word reading efficiency test (Moll \& Landerl, 2010) was an inclusion criterion of the reading-disabled group. The rationale guiding the choice of this measure was that single word reading has been shown to be a core and continuing difficulty in reading disability (Fletcher, 2009; Lyon et al., 2003). In addition, fluency in reading is the main difficulty of reading-disabled children (and adults) reading orthographies with transparent grapheme-phoneme relations such as the German orthography (e.g., de Jong \& van der Leij, 2003; van der Leij \& van Daal, 1999; Wimmer, 1993). Consequently, the examination of accuracy and rate of single word recognition is a common practice in the diagnosis of reading disability. A total of 29 children (11 boys, mean age $=11.61$ years, $S D=0.58$ ) were included in the group of reading-disabled children (10 children scored within the lowest 10th percentile and 19 scored between the 10th and 25th percentiles). Because the group of regular readers was significantly larger $(n=113), 34$ children were randomly selected ( 17 boys, mean age $=11.48$ years, $S D=0.59$ ) in order to be more comparable in size to the group of reading-disabled children. The assignment of participants into one of the two reading groups was further confirmed by a series of normed reading, spelling, and cognitive tests found to distinguish between regular readers and readers with reading disability (e.g., Breznitz \& Misra, 2003; Mayseless \& Breznitz, 2011). Regular readers outweighed reading-disabled children in all of these tests, as presented in Table S1 of the online supplementary material. These differences are consistent with recent scientific definitions of a reading disability (Lyon et al., 2003; Shaywitz \& Shaywitz, 2008). Notably, although the two groups differed significantly in vocabulary scores, the difference was very small. The background measures of the total sample representing a broad range of reading skills appear in Table S2 of the supplementary material. Parents confirmed in writing the participation of their children in the study. The experiment was approved by the institutional ethics committee.

\section{Materials}

\section{Background measures}

Silent reading. The Leseverständnistest für Erst-bis Sechstklässler, a reading comprehension test for first to sixth graders (ELFE 1-6; Lenhard \& Schneider, 2006), was administered. The test comprises three subtests: (a) word comprehension, (b) sentence comprehension, and (c) text comprehension. In the first subtest, children need to choose the name of an object presented as a picture out of 4 written words (72 words altogether). In the second subtest (consisting of 28 items), children are required to choose a word matching the context of a written sentence out of 4 written words. In the third subtest, children are required to read short paragraphs and to answer multiple-choice comprehension questions (20 paragraphs altogether). The test is restricted in time; children are stopped after $2 \mathrm{~min}$ in the word and sentence subtests and after $6 \mathrm{~min}$ in the text subtest. Two 
examples precede each sub-test. Each item correctly answered earns 1 point. Cronbach's alpha reliability coefficients of the subtests are between $\mathrm{a}=.92$ and $\mathrm{a}=.97$.

Spelling. The Diagnostischer Rechtschreibtest für 5. Klassen, a diagnostic spelling test for fifth graders (DRT-5; Grund, Haug, \& Naumann, 1995), was administered. A form was presented to the children with 51 written sentences, with one missing word per sentence. The experimenter read each sentence out loud, including the missing word, which children were required to write on a blank line in the form. The test focuses on basic vocabulary (nouns, adjectives, and verbs) that represent the most important spelling cases in the language. Notably, whereas the German orthography is considered transparent in reading, its sound-to-spelling relations are more opaque (as is the case with many other alphabetic orthographies; see Wimmer \& Mayringer, 2002). This characteristic of the German spelling, in addition to the type of words chosen in the test, means that the addressing of stored orthographic representations is required in order to succeed on the test. Split-half reliability is $r=.93$.

Oral reading. Two subtests from the Salzburger-Lese und Rechtschreibtest, a reading and spelling test (SLRT-II; Moll \& Landerl, 2010), were administered: reading of words and of pseudowords. Each subtest comprises a list of 156 items (nouns and verbs in the case of words) preceded by 8 example items. The items in the word reading test are arranged in eight columns ordered in an increasing level of difficulty as far as length, frequency, and word complexity (in terms of syllable structure) are concerned. The pseudowords were constructed based on legal structures in the language, but no real lexical parts (e.g., morphemes) were included. The items are also arranged in columns increasing in length and complexity. Children were instructed to read as fast and accurately as they could and were stopped after $1 \mathrm{~min}$ in each subtest. Each correct reading of a word/pseudoword earned 1 point. Parallel form reliability coefficients of the subtests are between .90 and .98 .

Cognitive skills. The Vocabulary subtest from the German version of the Wechsler Intelligence Scale for Children-IV (HAWIK-IV; Petermann \& Petermann, 2010) was administered. Other abilities, previously related to fluency in reading (Breznitz, 2006), were also tested. These included speed of processing, examined by the Symbol Search and Digit Symbol subtests from the HAWIK-IV, requiring children to rapidly process visually presented stimuli. Working memory was tested using the Digit Span task from the HAWIK-IV, requiring participants to repeat names of digits in the same order as presented by the experimenter as well as in reverse order. Reliability measures of the HAWIK-IV subtests are between $r=.76$ and $r=.91$. Verbal speed of processing was also assessed using a rapid automatized naming (RAN) task (after Wolf, Bowers, \& Biddle, 2000). Two forms of the RAN task were presented: RAN digits and RAN letters. Each comprises a table of 5 rows and 10 columns with reappearances of five different digits or letters. Children were asked to name each digit/letter as quickly as possible. Each correct naming earned 1 point, and performance time was recorded.

\section{Experimental material}

The task consisted of reading of sentences followed by multiple-choice comprehension questions with four alternative answers (one question followed each sentence). The sentences were taken from a bank of sentences originally compiled for the purpose of a previous study of regular readers of German in the third grade (Nagler et al., 2015; Nagler, Lonnemann, Linkersdörfer, Hasselhorn, \& Lindberg, 2013). High comprehension rates were found in this study, suggesting that the sentences could also be followed by fifth graders with reading disability. The sentences (132 altogether) were 
divided among six blocks in order to be presented in six different experimental conditions (i.e., 22 sentences were presented per block/condition). The mean length (number of letters) and complexity (number of clauses) of the sentences were comparable across blocks (length ranged from 97.07 to 98.43 , and complexity ranged from 1.79 to 1.89 ). To further verify that possible differences between the sentences will not intervene with the results, the blocks of sentences were counterbalanced among the six presentation conditions. Each participant saw each sentence only once. The comprehension questions and distracters were designed so that the sentences needed to be read in order for the children to be able to answer them correctly. Two examples preceded each condition.

The following experimental conditions were adapted from Breznitz (1987a).

Self-paced 1. Participants were presented with the following instruction: "Sentences will be presented on the computer screen, one sentence at a time. Read the sentence silently in your heart. Read it as you would normally read at your own pace. Press the space bar on the keyboard when reaching the end of the sentence. Note that you will be asked to answer a comprehension question of the multiple-choice type following each sentence. Try to answer as correctly as you can. Press the key matching the number of the correct answer on the keyboard, and then the next sentence will appear."

Four fast-paced conditions. Sentences were erased from the screen as follows: (a) letter by letter, (b) word by word, (c) prefix by morpheme and suffix, or (d) random unit of letters by random unit of letters (units of letters of random length and no lexical meaning). Each condition was presented as a separate block. The instruction was the same as in the self-pace 1 condition except for the instruction to read at one's normal reading pace. No explanations were given regarding the different manipulations on the presentation of texts.

Duration of letter presentation was set according to the reader's own mean per-letter reading rate in the self-paced 1 condition. In conditions (b) to (d), the presentation time of each unit manipulated was calculated by multiplying the individual per-letter reading rate by the number of letters in a unit manipulated. To ensure that the conditions compared met the same criteria, the rate of text deletion was kept constant across all fast-paced blocks.

The procedure was the same as in the self-paced condition; participants pressed the space bar when reaching the end of the sentence, thereby providing a measure of reading rate. A multiple-choice comprehension question appeared immediately thereafter, and children needed to press a key representing the correct answer (digits 1-4). The next sentence followed thereafter. The order of administration of the four fast-paced conditions was counterbalanced across participants.

Notably, in the previous studies examining the acceleration phenomenon (review in Breznitz, 2006), the sentences were presented on the screen in the fast-paced condition until the last letter was erased. In studies examining novice readers, who are still used to oral reading, children read all sentences out loud and an experimenter recorded accuracy and reading rate (Breznitz, 1987a, 1987b, 1997b, 1997c; Breznitz \& Share, 1992). This ensured that the sentences were indeed read. In studies using silent reading, the individual rate of text deletion (based on the self-paced 1 condition) was taken as a measure of performance rate (Breznitz et al., 1994). In the current study, fifth graders who are already used to the silent mode of reading were tested. To simulate their natural mode of reading (Bar-Kochva, 2013; Share, 2008), participants were instructed to read silently in all conditions. In view of intra-individual differences in the reading rate of different items (e.g., Breznitz, 1997b), it may well be that a child completes the reading of a sentence before it entirely disappears from the screen. In an attempt to obtain a more accurate measure of reading rate than the pace of 
text deletion, reading rate was separately calculated for each sentence according to the time taken from the presentation of the sentence until the child pressed the key terminating its presentation.

Self-paced 2. The self-paced condition needed to be presented before the fast-paced conditions because the rate at which texts were deleted was based on it. This left the possibility that effects of warm-up in the fast-paced conditions will intervene in the results (Breznitz, 1997a, 1997b). Therefore, we used the same procedure as Breznitz applied in her studies; after the fast-paced conditions, participants were asked to read once again at their own everyday reading rate and to answer comprehension questions. The instructions and procedure were the same as in the self-paced 1 condition.

\section{Procedure}

The silent reading (ELFE 1-6) and spelling (DRT-5) tests were administered in a class setting. All other tasks were administered individually in one session (lasting 1.0-1.5 h). Oral reading and the cognitive tests were administered in a counterbalanced manner across participants and were followed by the experimental task. In this task, participants read six blocks of sentences and answered a comprehension question after each sentence. The self-paced 1 condition was always presented first, then the fast-paced conditions appeared and were counterbalanced in order of administration across participants, and the self-paced 2 condition appeared last (Fig. 1). Children were informed at the beginning of each session about the types of tasks that would be administered and their length.

1. Self-paced 1
2. Fast paced:

a. Letters

b. Words

c. Morphemes, prefixes, and suffixes

d. Random non-lexical orthographic units (a-d

counterbalanced in order of presentation)
3. Self-paced 2

Fig. 1. Description of the experimental task.

\section{Results}

\section{Performance in different experimental conditions}

Fluency in reading was suggested to reflect accuracy and automaticity achieved in the processes that underlie reading (Wolf \& Katzir-Cohen, 2001), expressed by fast reading with good comprehension (Breznitz, 2006). Consequently, the measure of fluency in reading in the current study was defined as the reading rate of sentences correctly understood.

As mentioned in the Method section, participants could terminate the presentation of the sentences by pressing a key on the keyboard, thereby indicating that they had completed the reading of the sentence before it was entirely deleted from screen. This was allowed in order to obtain a measure of silent reading rate while taking into account variance in the reading rate of different sentences. The disadvantage of such a procedure, however, is that children could progress in the task without actually reading all sentences. A visual inspection of single trials pointed to some unreasonable 
reading rates that put the reading of the sentences in these trials into question. Some might not have been read at all, whereas others may have been only partially read. Therefore, certain preprocessing steps needed to be carried out in order to reduce the effect of responses that did not reflect actual reading. Trials in which the reading rate reached 50 letters per second and higher were regarded as invalid (accuracy in these trials did not exceed chance level) and, therefore, were excluded from analysis. This cutoff point was still considerably higher than the mean reading rates of the regular readers; therefore, additional inspection of outlier responses within each individual needed to be carried out. To this end, the reading rates were converted into $Z$ scores, calculated based on the individual performance across trials within each condition (i.e., the $Z$ score was calculated separately for each participant and experimental condition). Trials with $Z$ scores below -2 and above 2 were excluded from analysis. This left $77 \%$ of the trials to be analyzed.

Performance of children with and without reading disability in different experimental conditions

Reading rates and comprehension per condition and group are presented in Table 1. A repeatedmeasures analysis of variance (ANOVA) was carried out with reading rate in the six experimental conditions as a within-participant factor and group (reading-disabled children or regular readers) as a between-participant factor. A main effect was found for experimental condition, $F(5,188)=66.72, p=$ $.000, \eta \underset{p}{2}=.522$. Bonferroni pairwise comparisons indicated that fluency in all fast-paced conditions was better than in self-paced 1 ( $p=.000$ in all comparisons). Fluency in self-paced 2 was also better than in self-paced 1 but was lower than in the fast-paced conditions ( $p=.000$ in all comparisons except for the comparison with the deletion of random orthographic units, which was significant at $p$ $=.002)$. A main effect was also found for group, $F(1,61)=46.69, p=.000, \eta \underset{p}{2}=.434$, with regular readers showing better fluency in reading.

\section{Table 1}

Performance of reading-disabled children and regular readers in the experimental task

\begin{tabular}{ccccccccc}
\hline & \multicolumn{3}{c}{ RD } & \multicolumn{5}{c}{ RR } \\
\cline { 2 - 9 } & \multicolumn{1}{c}{ Minimum } & Maximum & Mean & SD & Minimum & Maximum & Mean & SD \\
\hline Fluency (number of letters read per second) & & & & & & \\
Self-paced 1 & 4.87 & 19.98 & 9.00 & 2.86 & 7.84 & 26.89 & 15.35 & 4.70 \\
Letter deletion & 7.26 & 20.91 & 12.14 & 3.07 & 10.00 & 37.98 & 21.07 & 6.68 \\
Word deletion & 6.70 & 22.14 & 11.75 & 3.04 & 11.54 & 37.20 & 21.10 & 6.55 \\
Morpheme deletion & 6.25 & 20.54 & 11.71 & 2.95 & 10.57 & 38.75 & 21.23 & 7.18 \\
Random deletion & 6.26 & 20.28 & 11.77 & 3.06 & 10.14 & 41.07 & 20.61 & 7.48 \\
Self-paced 2 & 5.38 & 16.02 & 10.52 & 2.23 & 9.79 & 35.04 & 18.97 & 6.32 \\
Comprehension (correct answers out of 22) & & & & & & \\
Self-paced 1 & 12.00 & 20.00 & 16.21 & 2.04 & 10.00 & 21.00 & 16.71 & 2.26 \\
Letter deletion & 6.00 & 21.00 & 15.46 & 3.19 & 14.00 & 22.00 & 18.24 & 2.13 \\
Word deletion & 11.00 & 22.00 & 16.97 & 2.77 & 13.00 & 21.00 & 18.24 & 1.99 \\
Morpheme deletion & 7.00 & 22.00 & 15.62 & 3.57 & 11.00 & 21.00 & 18.26 & 2.42 \\
Random deletion & 8.00 & 21.00 & 16.03 & 3.44 & 14.00 & 21.00 & 18.03 & 2.18 \\
Self-paced 2 & 6.00 & 19.00 & 13.46 & 3.51 & 5.00 & 20.00 & 15.26 & 3.30 \\
\hline
\end{tabular}

Note. RD, reading-disabled children; RR, regular readers.

There was also an interaction between experimental condition and group, $F(5,188)=7.37, p=.000$, $\eta \underset{p}{2}=.108$. To understand the direction of interaction, a repeated-measures ANOVA was carried out 
separately for each group. Main effects of experimental condition were found in both groups (reading-disabled children: $F(5,93)=35.56, \mathrm{p}=.000, \eta \underset{p}{2}=.559$; regular readers: $\mathrm{F}(5,89)=42.25, \mathrm{p}=$ $.000, \eta \underset{p}{2}=.561$ ). Bonferroni pairwise comparisons showed that in both groups fluency was better in all conditions than in self-paced 1 (reading-disabled children: $p=.000$ in all comparisons with the fast-paced conditions and $p=.004$ in comparison with self-paced 2; regular readers: $p=.000$ in all comparisons). In reading-disabled participants, fluency in the fast-paced conditions was better than in self-paced 2 ( $p=.002$ in comparison with letter-by-letter deletion and $p<.05$ in all other comparisons). Fluency in the fast-paced conditions was better than in self-paced 2 also in regular readers $(p=.000$ in comparison with word deletion and $p<.01$ in comparison with letter-by-letter deletion and morpheme deletion), with the one exception of the comparison between fluency in selfpaced 2 and deletion of random orthographic units being insignificant $(p=.122)$.

A repeated-measures ANOVA was also carried out on the measure of comprehension with experimental condition as a within-participant factor and group as a between-participant factor. A main effect of experimental condition was found, $F(5,240)=14.98, \mathrm{p}=.000, \eta_{p}^{2}=.197$. Bonferroni pairwise comparisons indicated that comprehension in self-paced 2 was lower than in all other conditions ( $p=.004$ in comparison with self-paced 1 and $p=.000$ in comparison with all fast-paced conditions). Word deletion was the only fast-paced condition in which better comprehension than in self-paced 1 was found $(p=.020)$. There was also a main effect for group, $F(1,61)=16.19, p=.000$, $\eta \underset{p}{2}=.210$, with higher comprehension rates being achieved by the regular readers. It should be noted, however, that although there was no significant interaction between group and experimental condition, the means presented in Table 1 suggest similar comprehension in the two groups under the self-paced 1 condition and an advantage of the regular readers in all other conditions (fast-paced and self-paced 2).

\section{Performance of the total sample in different experimental conditions}

To further confirm whether there were differences between the experimental conditions, another analysis was conducted on the larger sample representing a broad range of reading skills $(n=142)$. Reading rates and comprehension per condition of this sample are presented in Table 2. A repeated-measures ANOVA was carried out on the measure of fluency in reading with experimental condition entered as a within-participant factor. A main effect was found, $F(5,487)=177.49, \mathrm{p}=.000, \eta_{p}^{2}=.557$, and Bonferroni pairwise comparisons indicated that fluency in reading improved in all four fast-paced conditions compared with the two self-paced conditions ( $p=.000$ in all comparisons). The difference between the first and last self-paced conditions was also significant $(p=.000)$, with the latter showing better fluency.

A repeated-measures ANOVA was also carried out on the measures of comprehension with the experimental condition as a within-participant factor. A main effect was found, $F(5$, 592)=34.20, $p=.000, \quad \eta_{p}^{2}=.195$. Bonferroni pairwise comparisons indicated better comprehension when reading in any of the fast-paced conditions compared with self-paced 1 ( $p=.000$ compared with word deletion and $p<.05$ in the comparison with morpheme deletion and deletion of random orthographic units). One exception was comprehension in letter-by-letter deletion, which did not differ significantly from comprehension in self-paced 
1. Comprehension in the word-by-word condition was better than comprehension in the letter-by-letter condition $(p=.02)$. Comprehension in self-paced 2 was lower than in all other conditions ( $p=.000$ in all comparisons).

\section{Table 2}

Performance of the total sample representing a broad range of reading skills in the experimental task.

\begin{tabular}{ccccc}
\hline & Minimum & Maximum & Mean & SD \\
\hline Fluency (number of letters read per second) & & & \\
Self-paced 1 & 4.87 & 26.89 & 12.75 & 6.31 \\
Letter deletion & 7.26 & 40.15 & 17.83 & 6.27 \\
Word deletion & 6.70 & 38.96 & 17.71 & 6.34 \\
Morpheme deletion & 6.25 & 38.75 & 17.62 & 6.27 \\
Random deletion & 6.26 & 41.07 & 17.56 & 5.64 \\
Self-paced 2 & 5.38 & 35.04 & 15.80 & 2.19 \\
Comprehension (correct answers out of 22) & & & 2.56 \\
Self-paced 1 & 10.00 & 22.00 & 16.55 & 2.40 \\
Letter deletion & 6.00 & 22.00 & 17.15 & 2.99 \\
Word deletion & 8.00 & 22.00 & 17.89 & 2.75 \\
Morpheme deletion & 7.00 & 22.00 & 17.57 & 3.24 \\
Random deletion & 8.00 & 22.00 & 17.49 & 14.92 \\
Self-paced 2 & 5.00 & 20.00 & & \\
\hline
\end{tabular}

\section{Performance by order of presentation of different experimental conditions}

In previous studies examining the acceleration phenomenon (Breznitz, 1987a, 1987b, 1997a, 1997b, 1997c; Breznitz \& Share, 1992), no differences were found between the conditions of self-paced 1 and self-paced 2. In this study, however, fluency increased and comprehension decreased in selfpaced 2 compared with self-paced 1 , suggesting a speed-accuracy trade-off in the second self-paced condition. At the same time, there were no negative correlations between reading rates (letters read per $1 \mathrm{~s}$ ) and comprehension in self-paced 2; these variables did not correlate in the small samples and showed a positive correlation in the total sample $(r=.226, p=.007)$. The fact that invalid response rates were possible in the current study but not in previous ones led us to examine the possibility that the speed-accuracy trade-off in self-paced 2 is associated with such reading rates. The correlations between reading rate and comprehension, were therefore calculated again based on the raw data (which included the trials defined as invalid). A clear pattern of negative relations between response rates and comprehension was obtained in the total sample $(r=-.334, p=.000)$ and in reading-disabled children $(r=-.436, p=.02)$. In contrast, such effects were absent in the selfpaced 1 condition even when correlations were calculated based on the raw data; there were no correlations in the small samples, and there was a positive correlation between reading rate and comprehension in the total sample $(r=.218, p=.006)$.

The question arises why invalid reading rates would occur in self-paced 2 more than in self-paced 1. Another methodological difference between the current study and previous studies (Breznitz, 1987a, 1987b, 1997a, 1997b, 1997c; Breznitz \& Share, 1992) is that the current experimental task was considerably longer. It included four fast-paced conditions instead of one between the two selfpaced conditions, and each block included more trials (6 in most previous studies compared with 22 in the current study). Considering that participants could accelerate the progress in the task, they may have tended to overuse this possibility in blocks appearing late in order. In an attempt to test 
whether an effect of order was involved, we examined the frequency of invalid responses and error rates by order of presentation of the different experimental conditions (see Table S3 in the supplementary material). Because the order of presentation of the fast-paced conditions was counterbalanced between participants, we merged the invalid response rates and error rates of the different fast-paced conditions by the order of their presentation.

The frequencies of invalid responses suggested that there were more responses of this type as the children progressed in the task. The sums of invalid responses in the self-paced 1 and self-paced 2 conditions were compared using paired-samples t-tests, and these indicated marginally significant differences in reading-disabled children, $\mathrm{t}(28)=-2.05, \mathrm{p}=.05$, and significant differences in the total sample, $t(141)=-2.79, p=.006$. The same difference in regular readers only approached significance, $t(33)=-1.81, p=.081$; nevertheless, the larger number of invalid responses in self-paced 2 compared with self-paced 1 (Table S3) indicates that the comprehension score in self-paced 2 was based on fewer trials than the same score in self-paced 1 . These analyses may then support the possibility that the decline in comprehension in self-paced 2 resulted from an increase in trials omitted due to invalid response rates compared with conditions administered earlier in order.

A comparison of error rates between the two self-paced conditions would not contribute much to the understanding of whether an effect of order was involved in the decline in comprehension beyond the data already reported in Tables 1 and 2 (because their order of presentation was constant). Therefore, we further examined the possible effect of order by testing whether such an effect was cancelled out in the fast-paced conditions (administered second to fifth in order) through the counterbalancing of their order of presentation. The results suggest an increase in error rates in the blocks administered late compared with those administered early. Planned comparisons between the accuracy rates in the blocks administered second and fifth in order indicated significant differences in reading-disabled children, $t(28)=-2.29, p=.029$, and in the total sample, $t(141)=2.38$, $p=.019$. Therefore, while a possible effect of order of presentation may have been cancelled out in the case of the fast-paced conditions (at least in the case of reading-disabled children and the total sample), it may have still been observed in self-paced 2 , which was always administered sixth and last in order.

\section{Relations of phonological decoding and orthographic knowledge with fluency in reading}

The relations between fluency in reading with and without time constraints and the processes of reading in reading-disabled children and in regular readers were tested using regression analyses. Fluency rates in the six experimental conditions were entered as dependent variables. Reading of pseudowords and spelling were entered together as independent variables (using the "Enter" method, in which the independent variables are entered into the equation in one step). Reading of pseudowords is a commonly used measure to examine phonological decoding of small orthographic units (Share, 1995). The type of pseudowords used was expected to test such processes because none of the pseudowords included real lexical parts. As mentioned earlier, although the German orthography is considered transparent in reading, its spelling is more opaque and, therefore, requires specific orthographic knowledge. Spelling may, of course, also involve phonological sound-to-spelling conversion. At the same time, the type of words included in the spelling test used in this study (Grund et al., 1995) strongly suggests that phonological decoding processes could not suffice in order to succeed in the test. This measure, therefore, was considered to test processes associated with the addressing of orthographic representations. The assumption that the tasks of spelling and reading of 
pseudowords are indicators of different processes of reading may be further supported by an analysis of Pearson correlations: reading of pseudowords and spelling of real words correlated with word recognition in reading-disabled children $(r=.525, p<.01$ and $r=.391, p<.01$, respectively) and in regular readers $(r=.651, p<.01$ and $r=.644, p<.01$, respectively). However, reading of pseudowords and spelling did not correlate with one another in either group.

The results of the regression analyses are presented in Table 3. Reading of pseudowords explained a significant amount of variance in fluency in reading in the reading-disabled children across all experimental conditions, whereas in the regular readers spelling explained a significant amount of variance in the same measure of reading in all experimental conditions.

\section{Table 3}

Regression analyses predicting fluency in reading in each experimental condition by underlying processes of reading in reading-disabled children and regular readers.

\begin{tabular}{|c|c|c|c|c|c|c|c|c|c|c|}
\hline \multirow[t]{2}{*}{ Analysis } & \multicolumn{5}{|c|}{$\mathrm{RD}$} & \multicolumn{5}{|c|}{$\mathrm{RR}$} \\
\hline & B & SE & $\beta$ & $\mathrm{t}$ & Significance & B & $\mathrm{SE}$ & $\mathrm{B}$ & $\mathrm{t}$ & Significance \\
\hline \multicolumn{11}{|l|}{ Self-paced 1} \\
\hline 1 Ph. decoding & .247 & .060 & .649 & 4.102 & .000 & .110 & .068 & .268 & 1.629 & .115 \\
\hline Spelling & .017 & .052 & .053 & .335 & .741 & .338 & .122 & .454 & 2.764 & .010 \\
\hline 2 Ph. decoding & .184 & .062 & .501 & 2.950 & .007 & -.060 & .073 & -.152 & -.827 & .415 \\
\hline Word reading & .118 & .071 & .282 & 1.660 & .109 & .314 & .082 & .700 & 3.808 & .001 \\
\hline \multicolumn{11}{|l|}{ Letter deletion } \\
\hline 1 Ph. decoding & .229 & .069 & .572 & 3.318 & .003 & .042 & .085 & .071 & .488 & .630 \\
\hline Spelling & -.002 & .060 & -.007 & -.039 & .970 & .711 & .154 & .672 & 4.622 & .000 \\
\hline 2 Ph. decoding & .198 & .074 & .504 & 2.686 & .013 & -.156 & .097 & -.276 & -1.603 & .119 \\
\hline Word reading & .071 & .084 & .158 & .845 & .406 & .519 & .110 & .815 & 4.724 & .000 \\
\hline \multicolumn{11}{|l|}{ Word deletion } \\
\hline 1 Ph. decoding & .270 & .061 & .675 & 4.428 & .000 & .113 & .092 & .194 & 1.226 & .231 \\
\hline Spelling & .025 & .053 & .072 & .475 & .640 & .571 & .166 & .545 & 3.448 & .002 \\
\hline \multirow{3}{*}{$\begin{array}{ll}2 & \text { Ph. decoding } \\
\text { Word reading } \\
\text { Morpheme deleti }\end{array}$} & .217 & .064 & .557 & 3.405 & .002 & -.096 & .095 & -.173 & -1.007 & .322 \\
\hline & 109 & .073 & .245 & 1.499 & 146 & .482 & 107 & .772 & 4.491 & .000 \\
\hline & \\
\hline \multirow{2}{*}{$\begin{array}{l}1 \text { Ph. decoding } \\
\text { Spelling }\end{array}$} & .270 & .058 & .697 & 4.660 & .000 & .068 & .096 & .108 & .708 & .486 \\
\hline & .013 & .050 & .038 & .253 & .803 & .707 & .174 & .619 & 4.061 & .000 \\
\hline 2 Ph. decoding & .228 & .061 & .600 & 3.745 & .001 & -.130 & .113 & -.214 & -1.155 & .257 \\
\hline Word reading & .090 & .069 & .208 & 1.299 & .206 & .492 & 127 & .718 & 3.867 & .001 \\
\hline \multicolumn{11}{|l|}{ Random deletion } \\
\hline 1 Ph. decoding & .240 & .067 & .592 & 3.556 & .002 & 121 & .104 & 183 & 1.161 & .256 \\
\hline Spelling & .033 & .058 & .094 & .567 & .576 & .662 & .188 & .556 & 3.527 & .002 \\
\hline $2 \mathrm{Ph}$. decoding & .166 & .068 & .421 & 2.447 & .022 & -.069 & .122 & -.109 & -.567 & .575 \\
\hline Word reading & .162 & .077 & .359 & 2.085 & .047 & .448 & .137 & .627 & 3.260 & .003 \\
\hline \multicolumn{11}{|l|}{ Self-paced 2} \\
\hline 1 Ph. decoding & .178 & .046 & .614 & 3.902 & .001 & .132 & .089 & .234 & 1.481 & .151 \\
\hline Spelling & .047 & .039 & 187 & 1.187 & .247 & .531 & 161 & .521 & 3.291 & .003 \\
\hline 2 Ph. decoding & 140 & .048 & .494 & 2.902 & .008 & -.095 & .091 & -.178 & -1.049 & .302 \\
\hline Word reading & .092 & .055 & .286 & 1.678 & .106 & .473 & .102 & .784 & 4.616 & .000 \\
\hline
\end{tabular}

Note. RD, reading-disabled children; RR, regular readers; Ph., phonological. Two regression equations were tested for each condition and group. Fluency in reading in the different experimental conditions was entered as a dependent variable. In the first equation, reading of pseudowords and spelling were entered as independent variables in one step. In the second equation, reading of pseudowords and word reading were entered as independent variables in one step. The "Enter" method was used for both equations. 
To examine the role of efficiency in single word recognition in fluency in reading of sentences with and without time constraints, an additional analysis was carried out by including the measure of oral word reading (words per minute, SLRT-II, Moll \& Landerl, 2010) as an independent variable in the same regression analyses. The measure of word reading efficiency may involve both processes of phonological decoding and the reliance on orthographic representations, as suggested by the correlation analysis in both groups. At the same time, it includes a time factor that was absent in the measure of spelling and, thus, may provide additional information. However, the inclusion of word reading as an independent variable, together with spelling, suggested effects of multicollinearity in regular readers (low-significant to insignificant $t$ values of the coefficients, yet highly significant $F$ values, at $\mathrm{p}<.001$, of the overall regression analyses). Therefore, we included reading of pseudowords and word reading efficiency as independent variables in a second set of regression analyses (Table 3). Reading of pseudowords still explained a significant amount of variance in fluency in reading in reading-disabled children across all experimental conditions. Word reading explained a significant amount of variance in fluency in reading in this group only in the condition of deletion of random orthographic units. In regular readers, word reading was the significant predictor of fluency in reading in all conditions.

\section{Discussion}

This study set out to examine reading with and without time constraints while manipulating the duration of presentation of different orthographic units, and the relations between processes of reading (phonological decoding and the addressing of orthographic representations) and fluency in reading under these conditions. These issues are discussed first and are followed by a discussion of the possible potential and limitations of the manipulations examined.

\section{Reading performance with and without time constraints}

Participants read faster when the duration of presentation of texts was manipulated (all fast-paced conditions) than under no manipulation (self-paced reading) across all groups analyzed (children with reading disability, regular readers, and the total sample representing a broad range of reading skills). Another common finding in all analyses was that comprehension in the fast-paced conditions did not decline compared with self-paced reading. These results join those in a line of studies showing that time constraints enhance fluency in reading on-line and that the increase in reading rate (at least to a certain extent) does not come at the expense of comprehension (for reviews, see Breznitz, 2006, 2008).

Whereas in previous studies the duration in which texts were presented was manipulated by deleting one letter after the other, in the current study we examined the manipulation of different orthographic units - sublexical, lexical, and nonlexical units. The manipulation of all these units enhanced fluency in reading compared with self-paced reading, and there were no differences between the fast-paced conditions across the groups analyzed. These results stress the very principle of time constraints, regardless of the orthographic unit manipulated, as a central factor affecting fluency in reading.

Although in all analyses comprehension in the fast-paced conditions did not decline compared with self-paced reading, there were some differences between the samples. In the analyses of readingdisabled children and regular readers, there were no differences in comprehension between the fastpaced conditions and self-paced 1 with the exception of better comprehension in word deletion. 
However, the analysis of the total sample indicated better comprehension in all fast-paced conditions compared with self-paced 1 except in the case of letter-by-letter deletion, in which similar comprehension rates were obtained as in self-paced 1 . These discrepancies may have been the result of differences in statistical power between the samples analyzed. The findings indicating better comprehension in word deletion than in self-paced reading in all analyses suggest some advantage to this method of text deletion. At the same time, the advantage of manipulating words over other orthographic units may be modest (at least in the context examined here) given that the condition of word deletion did not show a consistent advantage over the other fast-paced conditions.

Performance in the self-paced 2 condition compared with self-paced 1 deviated from previous find ings examining the acceleration phenomenon (Breznitz, 1987a, 1987b, 1997a, 1997b, 1997c; Breznitz \& Share, 1992). In those studies, similar fluency and comprehension rates were obtained under these conditions. However, here fluency in self-paced 2 was better than in self-paced 1 , but comprehension declined, thereby suggesting a speed-accuracy trade-off in the second self-paced condition. It should be considered that a shorter duration of testing was applied in the previous studies (including only three conditions: self-paced 1, letter-by-letter deletion, and self-paced 2) than in the current one (which included six conditions: self-paced 1, four fast-paced conditions, and selfpaced 2). In addition, the number of sentences in each condition was considerably larger (6 in most previous studies compared with 22 in this study). At first glance, the increase in fluency may be explained by the fact that the self-paced 2 condition was presented after four conditions of fastpaced reading, which may have led the children to read the sentences in self-paced 2 with an emphasis on reading speed (which was absent in self-paced 1 ). Consequently, the reading rate may have become too high to allow good comprehension. A decline in comprehension when the pace of text deletion became too fast after several sessions of fast-paced training using the method of letterby-letter deletion was also found in a previous study by Snellings and colleagues (2009). At the same time, correlations between reading rates (number of letters read per second) and comprehension were negative in self-paced 2 only when invalid reading rates were taken into account. Whereas in the current study children could terminate the presentation of the sentences (thereby providing a measure of reading rate) before the entire text was deleted from the screen, in previous studies this was impossible. In other words, invalid reading rates were possible in the current study but not in previous studies. This suggests that the speed-accuracy trade-off might not be related to sentences that were read too fast to allow comprehension, but instead might be related to sentences that were actually not read or only partially read. Considering the length of the task and the fact that children could control their progress in it, it is possible that some children skipped the reading of more sentences as they tired of the task in an attempt to reach its end faster. Further analysis of the frequency of invalid response rates confirmed that there were more responses of this kind as children progressed in the task. Consequently, the comprehension score in self-paced 2 was based on fewer valid trials than the same score in self-paced 1. An analysis of error rates by order of presentation further confirmed that an effect of order was involved. Together, these results suggest that the source of the discrepant performance in the self-paced 2 condition in this study and in the previous studies is the two methodological differences between the studies: the length of the experimental task and the way in which the reading rate was measured.

\section{$\underline{\text { Relations between processes of reading and reading with and without time constraints }}$}

In line with the study's hypothesis, the analysis of self-paced reading indicated that in readingdisabled children phonological decoding explained a significant amount of variance in fluency in 
reading, whereas in regular readers it was spelling, the indicator of the addressed procedure, that explained a significant amount of variance in the same measure of reading. When spelling was replaced by word reading speed (which may involve the addressing of orthographic representations more than the reading of pseudowords and includes a speed factor that was absent in the measure of spelling), the general pattern remained; phonological decoding was the significant predictor of fluency in reading in reading-disabled children, and word reading explained a significant amount of variance in fluency in reading in regular readers. This finding corroborates previous results suggesting a qualitative difference in the processes underlying skilled and deficient reading (Bruck, 1990). Furthermore, the current finding pointing to strong relations between the indicator of the addressed procedure (spelling in particular) and fluency in reading in regular readers, but not in readingdisabled participants, is in line with the view that the addressing of previously acquired representations from the mental lexicon is an important component of efficient reading (Ehri, 2005; Harm \& Seidenberg, 2004; Share, 1995).

The direction of relations did not change when time constraints were imposed regardless of the orthographic unit manipulated. Namely, phonological decoding was a consistent predictor of fluency in reading across all conditions in reading-disabled children, and spelling and word reading were consistent predictors of this measure of reading across all conditions in regular readers. The only case in which word reading predicted fluency in reading in reading-disabled children was in the condition of deleting random orthographic units. Nevertheless, phonological decoding was still a significant predictor of fluency in reading in this condition. These results suggest that time constraints might not suffice in order to change the relations between the processes of reading examined and fluency in reading and that the manipulation of different orthographic units also does not encourage such change.

The current data then might not support the possibility that time constraints shift the emphasis away from phonological decoding in reading-disabled participants (Breznitz, 1997b; Karni et al., 2005). They also do not provide support to the possibility that the time constraints enhance retrieval from the mental lexicon (Breznitz, 1987a, 1997b, 2002), at least as far as the retrieval of orthographic representations in reading-disabled children is concerned. Although reading-disabled children can acquire orthographic representations (Share \& Shalev, 2004), these may be lacking or vague (Elbro, 1996). As a result, they might not be automatically retrieved even when the children are encouraged to do so when reading under time constraints. Consequently, phonological decoding may explain the variance in reading regardless of time constraints. These results suggest, then, that the improved fluency obtained under time constraints compared with self-paced reading in reading-disabled participants might not be ascribed to changes in the size of the orthographic unit processed in reading. These effects may be explained by the more general cognitive mechanisms previously associated with the acceleration phenomenon such as enhanced speed of processing of visual and auditory information, reduced distractibility, and increased attention capacity (Breznitz, 1988, 1997a, 2008; Breznitz \& Share, 1992). These are processes involved in reading but are not exclusive of reading.

\section{Potential and limitations of the manipulations examined}

As mentioned in the Introduction, the potential and limitations of manipulations applied on the presentation of texts leading to on-line effects on reading have rarely been examined. Despite the positive effects of time-restricted reading on fluency in reading, it must be acknowledged that the 
performance of reading-disabled children when reading under time constraints was still far behind the performance of regular readers when reading without time constraints. As should be expected, when the reading acceleration procedure was tested in the framework of a training program of several sessions (9-24), reading-disabled trainees could reach fluency in reading similar to that achieved by untrained regular readers (Breznitz et al., 2013; Snellings et al., 2009). In the study by Breznitz and colleagues (2013), which included more than twice as many training sessions than the study by Snellings and colleagues (2009), improved comprehension was also obtained and the positive effects on reading had remained in a long post-examination. Taken together, the results support the use of time constraints as a method of facilitating fluency in reading in everyday reading tasks using accessible technological devices (e.g., reading of electronic books); at the same time, it should be offered in addition to more demanding or long-term frameworks of training.

It remains to be established whether time-constrained reading has an effect on the addressing of orthographic representations in reading following a period of training or whether more specific methods of training aimed at enhancing orthographic representations are required (e.g., repeated exposures to frequent orthographic items). Another possibility is derived from the theoretical connection between speed of processing and the establishment of orthographic representations (Breznitz, 2006, 2008), according to which correct orthographic representations are generated in the mental lexicon when the timing of processing orthographic and phonological information is well regulated (see also Bowers \& Wolf, 1993). Based on the relations between deficits in speed of processing and reading disability (Breznitz, 2006; Wolf et al., 2002), the exposure to frequent orthographic items (whole words or morphemes) may be carried out under time constraints in an attempt to enhance their representation in the mental lexicon. From a practical point of view, such examinations may contribute to the ability to assist children with reading difficulties beyond the early stages of reading instruction, a population that has received less attention in the literature on reading intervention compared with novice readers. From a theoretical point of view, they may contribute to the understanding whether processes of reading can be normalized in reading-disabled children and adults or whether alternative processes of reading should be trained.

As far as comprehension is concerned, time constraints were suggested to contribute to this ability in different ways: by reducing memory load and distractibility and by increasing attention capacity (Breznitz, 1988, 1997a, 2006; Breznitz \& Share, 1992; Perfetti, 1985). At the same time, one limitation of time constraints on reading is the inability to go back and reread information, which may have a negative effect on comprehension, particularly when complex texts are presented (Nagler et al., 2013). It remains to be examined whether the method of text deletion should be combined with other methods aimed at enhancing comprehension (e.g., teaching reading strategies: paragraph summaries, repeated reading, making predictions, training awareness to structures of texts, learning to raise questions on texts while reading; for a review, see McNamara, 2012) in order to achieve consistent positive effects in the understanding of texts under time constraints. Furthermore, the possibility of combining the method of text deletion with an option of returning to erased texts may also be explored.

\section{Conclusions}

The current results confirm the on-line positive effect of time constraints on fluency in reading in various populations and indicate that the type of orthographic unit manipulated has no additional effect, at least in the context examined. The results also indicate a qualitative difference in the 
processes explaining the variance in skilled and deficient reading and suggest that time constraints might not have an effect on the relations between the processes of reading examined here and fluency in reading. It remains to be explored whether manipulating the duration of presentation of orthographic units of various sizes would bring about different results when administered as a method of training across a number of training sessions.

\section{Acknowledgments}

Support for this research was provided by the 7.FP, COFUND, Goethe International Postdoc Programme GO-IN (291776). The authors are greatly indebted to Telse Nagler and Sven Lindberg for providing the content for the experimental task and for their constructive advice. We also thank Björn Rump for his dedicated assistance in the programing of the experimental task, Mike Enslin and Debora Stechel for their role in data collection, and the schools and participants. 


\section{Appendix A. Supplementary data}

Supplementary data associated with this article can be found, in the online version, at http://dx.doi. org/10.1016/j.jecp.2015.06.012.

\section{References}

Aro, M., \& Wimmer, H. (2003). Learning to read: English in comparison to six more regular orthographies. Applied Psycholinguistics, 24, 621-635.

Bar-Kochva, I. (2013). What are the underlying skills of silent reading acquisition? A developmental study from kindergarten to the 2nd grade. Reading and Writing, 26, 1417-1436.

Bowers, P. G., \& Wolf, M. (1993). Theoretical links among naming speed, precise timing mechanisms, and orthographic skill in dyslexia. Reading and Writing, 5, 69-85.

Breznitz, Z. (1987a). Increasing first graders' reading accuracy and comprehension by accelerating their reading rates. Journal of Educational Psychology, 79, 236-242.

Breznitz, Z. (1987b). Reducing the gap in reading performance between Israeli lower- and middleclass first-grade pupils. Journal of Psychology, 121, 491-500.

Breznitz, Z. (1988). Reading performance of first graders: The effect of pictorial distractors. Journal of Research in Education, 83, 47-53.

Breznitz, Z. (1997a). Effects of accelerated reading rate on memory for text among dyslexic readers. Journal of Educational Psychology, 89, 289-297.

Breznitz, Z. (1997b). Enhancing the reading of dyslexic children by reading acceleration and auditory masking. Journal of Educational Psychology, 89, 103-113.

Breznitz, Z. (1997c). Reading rate acceleration: Developmental aspects. Journal of Genetic Psychology, 158, 427-441.

Breznitz, Z. (2002). Asynchrony of visual-orthographic and auditory-phonological word recognition processes: An underlying factor in dyslexia. Reading and Writing, 15, 15-42.

Breznitz, Z. (2006). Fluency in reading: Synchronization of processes. Mahwah, NJ: Lawrence Erlbaum.

Breznitz, Z., DeMarco, T., \& Hakerem, G. (1993). Topographic measures of cerebral activity during reading of text at fast- and slow-paced rates. Brain Topography, 6, 117-121.

Breznitz, Z., DeMarco, A., Shammi, P., \& Hakerem, G. (1994). Self-paced versus fast-paced reading rates and their effect upon comprehension and event-related potentials. Journal of Genetic Psychology, 155, 397-408.

Breznitz, Z., \& Leiken, M. (2000). Effects of accelerated reading rate on processing words' syntactic functions by normal and dyslexic readers: Event related potentials evidence. Journal of Genetic Psychology, 162, 276-296.

Breznitz, Z., \& Misra, M. (2003). Speed of processing of the visual-orthographic and auditoryphonological systems in adult dyslexics: The contribution of "asynchrony" to word recognition deficits. Brain and Language, 85, 486-502. 
Breznitz, Z. (2008). The origin of dyslexia: The asynchrony phenomenon. In G. Reid, A. Fawcett, F. Manis, \& L. Siegel (Eds.), The Sage handbook of dyslexia (pp. 11-29). Thousand Oaks, CA: Sage.

Breznitz, Z., \& Share, D. L. (1992). The effect of accelerated reading rate on memory for text. Journal of Educational Psychology, 84, 193-200.

Breznitz, B., Shaul, S., Horowitz-Kraus, T., Sela, I., Nevat, M., \& Karni, A. (2013). Enhanced reading by training with imposed time constraint in typical and dyslexic adults. Nature Communications, 4, 1486.

Bruck, M. (1990). Word-recognition skills of adults with childhood diagnoses of dyslexia. Developmental Psychology, 26, 439-454.

Bruck, M. (1992). Persistence of dyslexics' phonological awareness deficits. Developmental Psychology, 28, 874-886.

Burani, C., Marcolini, S., De Luca, M., \& Zoccolotti, P. (2008). Morpheme-based reading aloud: Evidence from dyslexic and skilled Italian readers. Cognition, 108, 243-262.

Clahsen, H. (1999). Lexical entries and rules of language: A multidisciplinary study of German inflection. Behavioral and Brain Sciences, 22, 991-1060.

Coltheart, M. (2005). Modeling reading: The dual-route approach. In M. Snowling \& C. Hulme (Eds.), The science of reading: A handbook (pp. 6-23). Oxford, UK: Blackwell.

Coltheart, M. (1978). Lexical access in simple reading tasks. In G. Underwood (Ed.), Strategies of information processing (pp. 151-216). New York: Academic Press.

de Jong, P. F., \& van der Leij, A. (2003). Developmental changes in the manifestation of a phonological deficit in dyslexic children learning to read in a normally achieving orthography. Journal of Educational Psychology, 95, 22-40.

Deacon, S. H., Parrila, R., \& Kirby, J. R. (2006). Processing of derived forms in high-functioning dyslexics. Annals of Dyslexia, 56, 103-128.

Deutsch, A., Frost, R., \& Forster, K. I. (1998). Verbs and nouns are organized and accessed differently in the mental lexicon: Evidence from Hebrew. Journal of Experimental Psychology, 24, 1238-1255.

Ehri, L. C. (2005). Learning to read words: Theory, findings, and issues. Scientific Studies of Reading, 9, 167-188.

Elbro, C. (1996). Early linguistic abilities and reading development: A review and hypothesis. Reading and Writing, 8, 453-485.

Farmer, M. E., \& Klein, R. M. (1995). The evidence for a temporal processing deficit linked to dyslexia: A review. Psychonomic Bulletin \& Review, 2, 460-493.

Fletcher, J. M. (2009). Dyslexia: The evolution of a scientific concept. Journal of the International Neuropsychological Society, 15, 501-508. 
Frith, U. (1985). Beneath the surface of developmental dyslexia. In K. E. Patterson, J. C. Marshall, \& M. Coltheart (Eds.), Surface dyslexia: Neuropsychological and cognitive studies of phonological reading (pp. 301-326). London: Lawrence Erlbaum.

Frost, R. (1998). Toward a strong phonological theory of visual word recognition: True issues and false trials. Psychological Bulletin, 123, 71-99.

Grund, M., Haug, G., \& Naumann, C. (1995). DRT-5: Diagnostischer Rechtschreibtest für 5 Klassen [DRT-5: Diagnostic spelling test for fifth graders]. Weinheim, Germany: Beltz.

Harm, M. W., \& Seidenberg, M. S. (2004). Computing the meanings of words in reading: Cooperative division of labor between visual and phonological processes. Psychological Review, 111, 662-720.

Horowitz-Kraus, T., Cicchino, N., Amiel, M., Holland, S., \& Breznitz, Z. (2014). Reading improvement in English- and Hebrew-speaking children with reading difficulties after reading acceleration training. Annals of Dyslexia, 64, 183-201.

Kail, R., \& Hall, L. K. (1994). Processing speed, naming speed, and reading. Developmental Psychology, 30, 949-954.

Karni, A., Morocza, I. A., Bitan, T., Kushnir, T., Shaul, S., \& Breznitz, Z. (2005). An fMRI study of the differential effects of word presentation rates (reading acceleration) on dyslexic readers' brain activity patterns. Journal of Neurolinguistics, 18, 197-219.

Katz, L., \& Frost, R. (1992). The reading process is different for different orthographies: The orthographic depth hypothesis. In R. Frost \& L. Katz (Eds.), Orthography, phonology, morphology, and meaning (pp. 67-84). Amsterdam: Elsevier.

Kuhn, M. R., \& Stahl, S. A. (2003). Fluency: A review of developmental and remedial practices. Journal of Educational Psychology, 95, 3-21.

Leiken, M., \& Breznitz, Z. (2001). Effects of accelerated reading rate on syntactic processing of Hebrew sentences among normal readers: Electrophysiological evidence. Genetic, Social, and General Psychology Monographs, 127, 193-211.

Leiken, M., \& Even Zur, H. (2006). Morphological processing in adult dyslexia. Journal of Psycholinguistic Research, 35, 471-490.

Lenhard, W., \& Schneider, W. (2006). ELFE 1-6: Ein Leseverständnistest für Erst- bis Sechstklässler [ELFE 1-6: A reading comprehension test for first to sixth graders]. Göttingen, Germany: Hogrefe.

Lyon, G. R., Shaywitz, S. E., \& Shaywitz, B. A. (2003). A definition of dyslexia. Annals of Dyslexia, 53, 114.

Mann, V., \& Wimmer, H. (2002). Phoneme awareness and pathways into literacy: A comparison of German and American children. Reading and Writing, 15, 653-682.

Mayseless, N., \& Breznitz, Z. (2011). Brain activity during processing objects and pseudo-objects: Comparison between adult regular and dyslexic readers. Clinical Neurophysiology, 122, 284-298. 
McNamara, D. S. (Ed.). (2012). Reading comprehension strategies: Theories, interventions, and technologies. New York: Psychology Press.

Meyer, M. S., \& Felton, R. H. (1999). Repeated reading to enhance fluency: Old approaches and new directions. Annals of Dyslexia, 49, 283-306.

Moll, K., \& Landerl, K. (2010). Lese- und Rechtschreibtest (SLRT-II): Weiterentwicklung des Salzburger Lese- und Rechtschreibtests (SLRT) [Reading and Spelling Tests, SLRT-II]. Bern, Switzerland: Hans Huber.

Nagler, T., Korinth, S., Linkersdörfer, J., Lonnemann, J., Rump, B., Hasselhorn, M., et al (2015). Text fading based training leads to transfer effects on children's sentence reading fluency. Frontiers in Psychology, 6. http://dx.doi.org/10.3389/fpsyg.2015.00119.

Nagler, T., Lonnemann, J., Linkersdörfer, J., Hasselhorn, M., \& Lindberg, S. (2013). The impact of reading material's lexical accessibility on text fading effects in children's reading performance. Reading and Writing, 27, 841-853.

Perfetti, C. A. (1985). Reading ability. New York: Oxford University Press.

Petermann, F., \& Petermann, U. (2010). HAWIK-IV: Hamburg-Wechsler Intelligenztest für Kinder-IV [Wechsler Intelligence Scale for Children (WISC-IV)-German version]. Bern, Switzerland: Huber.

Plaut, D. C. (2005). Connectionist approaches to reading. In M. J. Snowling \& C. Hulme (Eds.), The science of reading: A handbook (pp. 24-38). Malden, MA: Blackwell.

Raveh, M., \& Schiff, R. (2008). Visual and auditory morphological priming in adults with developmental dyslexia. Scientific Studies of Reading, 12, 221-252.

Roberts, G., Torgesen, J. K., Boardman, A., \& Scammacca, N. (2008). Evidence-based strategies for reading instruction of older students with learning disabilities. Learning Disabilities Research \& Practice, 23, 63-69.

Schiff, R., \& Raveh, M. (2007). Deficient morphological processing in adults with developmental dyslexia: Another barrier to efficient word recognition? Dyslexia, 13, 110-120.

Seymour, P. H. K., Aro, M., \& Erskine, J. M. (2003). Foundation literacy acquisition in European orthographies. British Journal of Psychology, 94, 143-174.

Share, D. L. (1995). Phonological recoding and self-teaching: Sine qua non of reading acquisition. Cognition, 55, 151-218.

Share, D. L. (2008). On the Anglocentricities of current reading research and practice: The perils of overreliance on an "outlier" orthography. Psychological Bulletin, 134, 584-615.

Share, D. L., \& Shalev, C. (2004). Self-teaching in normal and disabled readers. Reading and Writing, $17,769-800$.

Shaywitz, S. E., \& Shaywitz, B. A. (2008). Paying attention to reading: The neurobiology of reading and dyslexia. Development and Psychopathology, 20, 1329-1349. 
Snellings, P., van der Leij, A., de Jong, P. F., \& Blok, H. (2009). Enhancing the reading fluency and comprehension of children with reading disabilities in an orthographically transparent language. Journal of Learning Disabilities, 42, 291-305.

Thaler, V., Ebner, E. M., Wimmer, H., \& Landerl, K. (2004). Training reading fluency in dysfluent readers with high reading accuracy: Word specific effects but low transfer to untrained words. Annals of Dyslexia, 54, 89-113.

Traficante, D., Marcolini, S., Luci, A., Zoccolotti, P., \& Burani, C. (2011). How do roots and suffixes influence reading of pseudowords: A study of Italian children with and without dyslexia. Language and Cognitive Processes, 26, 777-793.

van der Leij, A., \& van Daal, V. H. P. (1999). Automatization aspects of dyslexia: Speed limitations in word identification, sensitivity to increasing task demands, and orthographic compensation. Journal of Learning Disabilities, 32, 417-428.

Verhoeven, L., \& Schreuder, R. (2011). Morpheme frequency effects in Dutch complex word reading: A developmental perspective. Applied Psycholinguistics, 32, 483-498.

Wimmer, H. (1993). Characteristics of developmental dyslexia in a regular writing system. Applied Psycholinguistics, 14, 1-33.

Wimmer, H., \& Mayringer, H. (2002). Dysfluent reading in the absence of spelling difficulties: A specific disability in regular orthographies. Journal of Educational Psychology, 94, 272-277.

Wolf, M., Bowers, G. P., \& Biddle, K. (2000). Naming speed processes, timing, and reading: A conceptual review. Journal of Learning Disabilities, 33, 387-407.

Wolf, M., Goldberg-O'Rourke, A., Gidney, C., Lovett, M., Cirino, P., \& Morris, R. (2002). The second deficit: An investigation of the independence of phonological and naming-speed deficits in developmental dyslexia. Reading and Writing, 15, 43-72.

Wolf, M., \& Katzir-Cohen, T. (2001). Reading fluency and its intervention. Scientific Studies of Reading, 5, 211-239.

Zorzi, M., Barbiero, C., Facoetti, A., Lonciari, I., Carrozzi, M., Montico, M., et al (2012). Extra large letter spacing improves reading in dyslexia. Proceedings of the National academy of Sciences of the United States of America, 109, 11455-11459. 